\title{
PERBANDINGAN METODE SARIMA DAN METODE TRANSFER PADA PRODUKSI PADI DI KABUPATEN KENDAL
}

\author{
(The Comparison SARIMA and Tansfer Methods On Rice Production In Kendal District)
}

\author{
Safaat Yulianto ${ }^{1 *}$, Ahmad Jauharudin Najib ${ }^{2}$ \\ 1,2Akademi Statistika (AIS) Muhammadiyah Semarang \\ *email: safaatyulianto@yahoo.com
}

\begin{abstract}
ABSTRAK
Indonesia merupakan negara agraris, artinya pertanian merupakan pemegang peranan penting bagi perekonomian nasional. Berdasarkan data dari Badan Pusat Statistik pada tahun 2017 yang menyatakan pertanian merupakan salah satu sektor yang paling berkonstribusi terhadap perekonomian nasional dengan konstribusi sebesar 13,14 persen. Pada sektor pertanian ini padi merupakan komoditas penghasil produksi terbesar dibanding komoditas lainnya dengan produksi sebesar 79 juta ton pada tahun 2016. Sebagai negara dengan jumlah penduduk yang besar maka Indonesia menghadapi tantangan dalam memenuhi kebutuhan padi, namun beralih fungsinya lahan pertanian menjadi non pertanian sangat berpengaruh pada hasil produksi tanaman padi, semakin berkurangnya luas lahan maka semakin berkurang pula produksi padi yang dihasilkan. Tidak terkecuali di Kabupaten Kendal yang memiliki daerah agraris dengan komoditas utama yaitu padi, hasil produksi padi di kabupaten ini cenderung mengalami penurunan pada tahun 2016 dan 2017. Untuk membantu pemerintah dalam menetapkan kebijakan dalam ketersediaan pangan digunakanlah analisis peramalan. Metode yang paling sering digunakan dalam peramalan adalah metode ARIMA. Metode ini sebenarnya sudah cukup baik, tetapi karena produksi padi juga dipengaruhi oleh luas lahan panen maka diusulkan metode fungsi transfer yang dapat memasukkan variabel luas panen ke dalam model peramalan. Data yang digunakan dalam penelitian ini adalah data produksi padi dan luas panen di Kabupaten Kendal dari bulan Januari 2013 hingga bulan Desember 2017. Hasil pengujian dengan menggunakan metode peramalan fungsi transfer menghasilkan model terbaik
\end{abstract}

Kata Kunci : Fungsi Transfer; Peramalan; Sarima

\section{ABSTRACT}

Indonesia is an agrarian country, meaning that agriculture holds an important role for the national economy. Based on data from the Central Statistics Agency in 2017 which states agriculture is one of the sectors that most contribute to the national economy with a contribution of 13.14 percent. In this agricultural sector, rice is the largest producer of production compared to other commodities with a production of 79 million tons in 2016. As a country with a large population, Indonesia faces challenges in meeting the needs of rice, but shifting the function of agricultural land to non-agriculture is very influential on yield rice production, the less land area, the less rice production is produced. No exception in Kendal Regency which has an agrarian area with the main commodity, rice, rice production in this Regency tends to decrease in 2016 and 2017. To assist the government in setting policies in food availability, forecasting analysis is used. The method most often used in forecasting is the ARIMA method. This method is actually quite good, but because rice production is also influenced by the area of harvested land, a transfer function method is proposed that can include the harvested area variable in the forecasting model. The data used in this study are data on rice production and harvested area in Kendal Regency from January 2013 to December 2017. The test results using the transfer function forecasting method produce the best model 


\section{PENDAHULUAN}

Menurut Badan Pusat Statistik, struktur perekonomian Indonesia didominasi oleh tiga sektor dan salah satunya yaitu pertanian yang berkonstribusi sebesar 13,14 persen(BPS, 2017b). Selain itu peran penting pertanian bagi perekonomian nasional juga dapat ditunjukkan oleh banyaknya penduduk yang hidup dengan bekerja pada sektor pertanian (Tunjung, 2010), artinya sektor pertanian selain membantu dalam penyerapan tenaga kerja, juga membantu menghasilkan bahan pangan, pendorong terciptanya industri lain, pendorong terciptanya usaha pada kegiatan lain, dan juga sektor yang menghasilkan devisa yang besar (Soekartawi, 2009).

Menurut Badan Pusat Statistik sektor pertanian terdiri dari beberapa sub sektor, diantaranya sub sektor tanaman pangan, peternakan, perikanan dan kehutanan (BPS, 2018). Beberapa sub sektor tersebut bila ditangani dengan serius tentu akan memberikan dampak yang besar dalam perkembangan ekonomi Indonesia pada masa mendatang. Pada sub sektor tanaman pangan, padi merupakan sumber penghasil terbesar dalam sub sektor tersebut. Kementrian Pertanian merilis data bahwa produksi padi Indonesia pada tahun 2016 mencapai angka 79 juta ton, lebih besar dari jagung dan kedelai yang masing - masing hanya memproduksi sebesar 23 juta ton dan 1 juta ton (Kementrian Pertanian Indonesia, 2017). Maka dapat dikatakan bahwa padi merupakan tanaman dengan komoditas yang penting (Sitohang, Siregar, \& Putri, 2013).

Sebagai negara dengan jumlah penduduk yang besar maka Indonesia menghadapi tantangan dalam memenuhi kebutuhan padi (Pratiwi, 2016). Apalagi bersamaan dengan pertumbuhan penduduk dan pesatnya pembangunan di berbagai bidang, lahan produksi padi beralih fungsi dari lahan pertanian menjadi non pertanian, yang sangat berpengaruh pada hasil produksi tanaman padi. Semakin berkurangnya luas lahan maka semakin berkurang pula produksi padi yang dihasilkan (BPS, 2018).

Menurut Kementrian Pertanian prosentase produksi padi di Provinsi Jawa Tengah pada tahun 2015 mencapai 14,99 persen dari produksi padi nasional. Hal tersebut membuat Provinsi Jawa Tengah sebagai salah satu daerah penghasil padi terbesar di Indonesia. Kabupaten Kendal merupakan kabupaten/kota yang berada di Provinsi Jawa Tengah. Kabupaten ini bias dikatakan sebagai daerah yang memiliki wilayah agraris karena 25,93 persen lahan di daerah ini digunakan sebagai tanah sawah, 20,89 persen tegalan, 15,69 persen hutan, 7,85 persen perkebunan, 23,71 lahan bukan pertanian, dan 5,93 persen lain-lain (BPS, 2017a). Oleh karena itu, diperlukan suatu penelitian untuk memperkirakan jumlah produksi padi pada tahun mendatang, sehingga pemerintah dapat menetapkan kebijakan apa yang akan diambil dalam mengatasi hal tersebut, serta pemerintah dapat bekerjasama dengan petani dan instansi terkait dalam melakukan peningkatan produksi padi.

Salah satu metode untuk memperkirakan jumlah produksi padi yaitu peramalan yang merupakan untuk melihat naik turunnya produksi padi yang tidak menentu. Penelitian sebelumnya pernah dilakukan oleh (Krismiasari, 2012) yaitu tentang peramalan produksi padi di Kabupaten Kampar dengan metode Box-Jenkins yang hanya menggunakan satu variabel saja, sedangkan untuk mengestimasi produksi padi dilakukan oleh (Sari \& Sukojo, 2015). Namun dalam penelitian lain disebutkan bahwa terdapat faktor lain yang dapat mempengaruhi jumlah produksi padi (Jumiati, 2016; Mantiri, Rotinsulu, \& Murni, 2015). Faktor lain yang dapat mempengaruhi produksi padi diantaranya luas panen (Ekaputri, 2008), sehingga perlu dilakukan penelitian menggunakan metode yang dapat memasukkan pengaruh faktor lain kedalam model peramalan produksi padi. Metode yang diusulkan yaitu metode fungsi transfer atau dikenal dengan nama lain ARIMAX ini merupakan model 
gabungan antara pendekatan regresi dan time series (Febriansyah \& Abadyo, 2013; Nisak, 2010; Siswanti, 2011). Metode Fungsi Transfer pernah digunakan dan terbukti baik dalam meramalkan harga komoditas stategis di Indonesia (Anggraeni, Boga, \& Mahananto, 2018). Selain itu pernah juga digunakan dalam meramalkan permintaan pakaian anak(Anggraeni, Vinarti, \& Kurniawati, 2015).

\section{METODE}

Data yang digunakan pada penelitian ini berupa data kuantitatif, yang merupakan data sekunder tentang produksi padi khususnya padi sawah dan luas panen yang diperoleh dari Dinas Pertanian dan Pangan di Kabupaten Kendal yang mupakan data time series. Time series merupakan suatu rangkaian pengamatan yang disusun berdasarkan periode waktu tertentu (Grandell, 2000). Periode waktu itu dapat berupa periode harian, mingguan, bulanan, tahunan dan lain sebagainya. Data time series sangat berguna untuk memperkirakan kejadian di masa lalu, karena pola perubahan beberapa periode lampau diyakini akan terulang pada masa kini (Haris, 2010).

Salah satu bentuk pemodelan data series menggunakan autoregressive integrate moving average (ARIMA) yang saat ini telah dipelajari secara luas pertama kali dipopulerkan oleh George Box dan Gwylim Jenkins pada tahun 1970-an. Oleh karena itu model autoregressive integrate moving average (ARIMA) ini juga sering disebut sebagai model Box-Jenkins (Makridakis et al., 1999). Bentuk umum dari model $\operatorname{ARIMA}(\mathrm{p}, \mathrm{d}, \mathrm{q})$ adalah

$$
\emptyset_{p}(B)(1-B)^{d} y_{t}=\theta_{q}(B) \alpha_{t}
$$

Suatu proses ARIMA dapat digambarkan dengan dimensi $p, d, q$ dengan:

AR $: p=$ orde dari proses autoregressive

$\mathrm{I}: \mathrm{d}=$ orde dari proses pembedaan (degree of differencing)

MA : $\mathrm{q}=$ orde dari proses moving average

Seasonal ARIMA merupakan model ARIMA untuk menghadapi fluktuasi data musiman. Karena diketahui bahwa model ARIMA merupakan model yang fleksibel untuk berbagai macam data deret waktu (Purnomo, 2015). Model seasonal ARIMA secara umum ditulis dengan notasi sebagai ARIMA $(p, d, q)(P, D, Q)^{s}$. Adapun bentuk persamaan umum dari model seaseonal ARIMA adalah:

$$
\Phi_{P}\left(B^{s}\right) \emptyset_{p}(B)(1-B)^{d}\left(1-B^{s}\right)^{D} y_{t}=\theta_{q}(B) \Phi_{Q}\left(B^{s}\right) \alpha_{t}
$$

dengan

$(p, d, q)=$ bagian tidak musiman dari model

$(\mathrm{P}, \mathrm{D}, \mathrm{Q})=$ bagian musiman dari model

$\mathrm{P} \quad=$ orde musiman untuk AR

$\mathrm{D} \quad=$ banyaknya differencing musiman

$\mathrm{Q} \quad=$ orde musiman untuk $\mathrm{MA}$

$\mathrm{s} \quad=$ jumlah periode per musim 
Model fungsi transfer adalah suatu model yang menggambarkan nilai prediksi masa depan dari suatu time series didasarkan pada nilai-nilai masa lalu time series itu sendiri dan satu atau lebih 585 endal 585 e yang berhubungan dengan outputseries tersebut (Wei, 2006). Bentuk umum persamaan model fungsi transfer dengan single input (xt) dan single output (yt) adalah:

$$
y_{t}=\mathrm{v}(\mathrm{B}) \mathrm{x}_{\mathrm{t}}+\eta_{\mathrm{t}}
$$

dengan:

$y_{t}=$ variabel dependent $/$ deret output

$\mathrm{x}_{\mathrm{t}}=$ variabel independent $/$ deret input

$\eta_{\mathrm{t}}=$ komponen error (deret noise) yang mengikuti model ARIMA

$$
\mathrm{v}(\mathrm{B})=\left(v_{0}+v_{1} B+v_{2} B^{2}+\cdots+v_{k} B^{k}\right)
$$

$\mathrm{k}$ merupakan orde fungsi transfer

karena $\mathrm{v}(\mathrm{B})=\frac{\omega(B)}{\delta(B)}$ dan $\eta_{\mathrm{t}}=\frac{\theta(B)}{\emptyset(B)} \alpha_{t}$

maka $y_{t}=\frac{\omega(B)}{\delta(B)} x_{t-b}+\frac{\theta(B)}{\emptyset(B)} \alpha_{t}$

dengan:

$\omega(B)=$ operator moving average orde $\mathrm{s}$

$\delta(B)=$ operator autoregressive orde $r$

\section{HASIL DAN PEMBAHASAN}

Untuk mengetahui gambaran umum produksi padi di Kabupaten Kendal pada bulan Januari tahun 2013 hingga bulan Desember 2017 dapat dilihat pada gambar berikut ini:

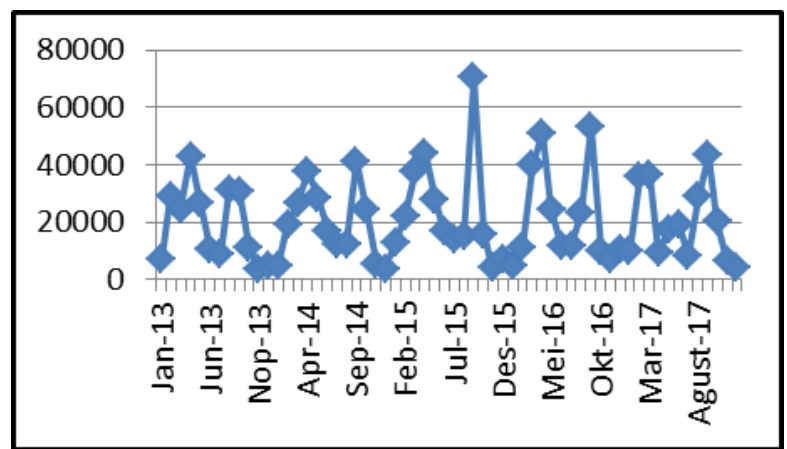

Gambar 1. Produksi Padi 2013-2017 
Berdasarkan Gambar 1 dapat diketahui bahwa hasil produksi padi di Kabupaten Kendal selalu mengalami kenaikan dan penurunan disetiap bulannya. Produksi padi tertinggi diketahui sebesar 70.444 ton terjadi pada bulan September tahun 2015, sedangkan produksi padi terendah diketahui sebesar 3.478 ton terjadi pada bulan November tahun 2013.

\section{Analisis Model SARIMA}

Hasil pendugaan produksi padi berdasarkan metode ARIMA diperoleh model SARIMA $(0,0,1)(1,1,1)^{12}$ dengan hasil pendugaan pada Tabel 1 dan Tabel $\mathbf{2}$.

Tabel 1 Estimasi Parameter Model SARIMA $(0,0,1)(1,1,1)^{12}$

\begin{tabular}{lcccc}
\hline \multicolumn{1}{c}{ Tipe } & Koef & SE koef & T & P-Value \\
& & & & \\
\hline SAR 12 & $-0,9789$ & 0,1569 & $-6,24$ & 0,000 \\
\hline MA 1 & 0,6494 & 0,1510 & 4,30 & 0,000 \\
\hline SMA 12 & 0,7137 & 0,2518 & 2,83 & 0,008 \\
\hline Konstanta & 0,10908 & 0,0059 & 18,38 & 0,000 \\
& & & \\
\hline
\end{tabular}

Tabel 2 Pengujian Model SARIMA $(0,0,1)(1,1,1)^{12}$

\section{Pengujian Keputusan}

Uji Parameter signifikans

\begin{tabular}{ll}
\hline Uji White Noise & white noise \\
\hline Normalitas Residu & normal
\end{tabular}

Dengan hasil pada Tabel 1 dan Tabel 2 maka model SARIMA $(0,0,1)(1,1,1)^{12}$ memenuhi semua asumsi.

\section{Analisis Model Transfer}

Hasil pendugaan produksi padi berdasarkan metode Transfer berdasarkan model ARIMA dari model input luas panen diperoleh model dugaan ARIMA $(1,0,0)$ dengan hasil pendugaan pada Tabel 3.

Tabel 3 Estimasi Parameter Model ARIMA $(0,0,1)$

\begin{tabular}{lllll}
\hline Tipe & Koef & SE koef & T & P-Value \\
\hline AR $\quad \mathbf{1}$ & 0,4697 & 0,1305 & 3,60 & 0,001 \\
\hline Konstanta & 4,20611 & 0,09935 & 42,33 & 0,000
\end{tabular}


Keterangan : ${ }^{*}$ ) nyata pada $a=5 \%$

Dari parameter dugaan pada Tabel 3, selanjutnya diuji apakah parameter - parameter tersebut signifikan atau tidak. Hasilnya adalah sebagai berikut:

Tabel 4 Parameter Akhir Model fungsi Transfer

\begin{tabular}{|c|c|c|c|c|}
\hline No & Nilai $b, r, s$ & Parameter & P-value & Keterangan \\
\hline \multirow{2}{*}{1} & \multirow{2}{*}{$0,1,0$} & $\omega_{0}$ & 0.0001 & Signifikan \\
\hline & & $\delta_{1}$ & 0.0001 & Signifikan \\
\hline \multirow{3}{*}{2} & \multirow{3}{*}{$0,1,1$} & $\omega_{0}$ & 0.0001 & Signifikan \\
\hline & & $\omega_{1}$ & 0.0001 & Signifikan \\
\hline & & $\delta_{1}$ & 0.0001 & Signifikan \\
\hline \multirow{4}{*}{3} & \multirow{4}{*}{$0,1,2$} & $\omega_{0}$ & 0.0001 & Signifikan \\
\hline & & $\omega_{1}$ & 0.0001 & Signifikan \\
\hline & & $\omega_{2}$ & 0.2907 & Tidak signifikan \\
\hline & & $\delta_{1}$ & 0.0001 & Signifikan \\
\hline \multirow{5}{*}{4} & \multirow{5}{*}{$0,2,2$} & $\omega_{0}$ & 0.0001 & Signifikan \\
\hline & & $\omega_{1}$ & 0.3815 & Tidak signifikan \\
\hline & & $\omega_{2}$ & 0.8395 & Tidak signifikan \\
\hline & & $\delta_{1}$ & 0.3848 & Tidak signifikan \\
\hline & & $\delta_{2}$ & 0.8251 & Tidak signifikan \\
\hline
\end{tabular}

Berdasarkan Tabel 4 dapat diketahui bahwa masih terdapat 2 model yang signifikan yaitu model $(0,1,0)$ dan model $(0,1,1)$, kemudian langkah selanjutnya adalah 2 model tersebut diuji autokorelasi residual dan korelasi silang antara residual dengan deret input.

a. Uji autokorelasi residual

Untuk menguji apakah terjadi autokorelasi residual dengan cara melihat pada tabel berikut

Tabel 5 Uji Autokorelasi Residual

\begin{tabular}{lcccc}
\hline No & Model & lag & $P$-value & Keterangan \\
\hline 1 & & 6 & 0.0429 & terjadi autokorelasi \\
\cline { 3 - 5 } & $0,1,0$ & & & \\
\cline { 3 - 5 } & & 12 & 0.001 & terjadi autokorelasi \\
\cline { 3 - 5 } & & 18 & 0.001 & terjadi autokorelasi \\
\cline { 3 - 5 } & & 24 & 0.0004 & terjadi autokorelasi \\
\hline 2 & $0,1,1$ & 6 & 0.4241 & tidak terjadi autokorelasi \\
\hline
\end{tabular}




\begin{tabular}{ccc}
12 & 0.7572 & tidak terjadi autokorelasi \\
\hline 18 & 0.9276 & tidak terjadi autokorelasi \\
\hline 24 & 0.9512 & tidak terjadi autokorelasi
\end{tabular}

Berdasarkan Tabel 5 diatas maka model yang memenuhi adalah model $(0,1,1)$ karena model tidak terjadi autokorelasi.

b. Uji korelasi silang antara residual dengan deret input

Selanjutnya untuk menguji apakah pada model 0,1,1 terjadi korelasi silang antara residual dengan deret inputatau tidak maka dengan cara melihat pada tabel berikut

Tabel 6 Uji Korelasi Silang Residual dengan Deret Input

Crosscorrelation Check of Residual with Inputx

\begin{tabular}{cccccccccc}
\hline $\begin{array}{c}\text { To } \\
\text { Lag }\end{array}$ & $\begin{array}{c}\text { Chi- } \\
\text { square }\end{array}$ & DF & PrChisq & \multicolumn{5}{c}{ Crosscorrelations } \\
\hline 5 & 1.74 & 5 & 0.6290 & 0.034 & -0.155 & 0.026 & 0.017 & -0.114 & 0.017 \\
\hline 11 & 3.57 & 9 & 0.9374 & 0.161 & 0.123 & 0.015 & 0.001 & -0.011 & -0.014 \\
\hline 17 & 6.95 & 15 & 0.9591 & -0.080 & 0.002 & 0.081 & -0.050 & -0.221 & 0.111 \\
\hline 23 & 12.38 & 21 & 0.9287 & 0.167 & 0.172 & -0.039 & -0.034 & -0.074 & -0.240 \\
\hline
\end{tabular}

Berdasarkan Tabel 6 dengan melihat pada kolom PrChisq $>0.05$ maka tidak terjadi korelasi antara residual dengan deret input.

Maka dari model $(0,1,1)$ yang telah memenuhi persyaratan sebagai model fungsi transfer dengan parameter $\mathrm{b}=0, \omega=1$, dan $\delta=1$.

\section{Perbandingan Model Sarima dan Model Transfer}

Hasil pendugaan produksi padi berdasarkan model Sarima dan model Transfer dibandingkan dengan melihat nilai MSE kedua model tersebut pada Tabel 4.

Tabel 4 Perbandingan Model Pendugaan SARIMA dan Transfer

\begin{tabular}{cc}
\hline Model & MSE \\
\hline SARIMA & 488,8579 \\
\hline Transfer & 343,2972 \\
\hline
\end{tabular}

\section{KESIMPULAN}

1. Hasil produksi padi di Kabupaten Kendal dalam waktu 5 tahun yaitu tahun 2013 sampai 2017 selalu mengalami kenaikan dan penurunan disetiap bulannya. Produksi padi tertinggi diketahui sebesar70.444 ton terjadi pada bulan September tahun 2015. Sedangkan produksi padi terendah diketahui sebesar 3.478 ton terjadi pada bulan November tahun 2013. Jika di rata-rata hasil 
produksi padi dalam waktu 5 tahun memperoleh hasil sebesar 20.892 ton, hasil tersebut merupakan angka yang cukup tinggi dalam produksi padi.

2. Peramalan produksi padi dapat dilakukan dengan 2 metode yakni metode SARIMA dan metode fungsi Transfer tergantung ketersediaan data penyerta, dalam kasus produksi padi kabupaten Kendal peramalan dengan metode fungsi transfer menghasilkan hasil yang lebih baik dengan melihat nilai MSE lebih kecil dibandingkan metode SARIMA

3. Hasil pengujian model peramalan terbaik dengan menggunakan metode fungsi transfer menghasilkan model yaitu

$$
y_{t}=\frac{1.03403-0.97223(B)}{1-0.94937(B)} X_{t}+\frac{\alpha_{t}}{1-0.85705(\mathrm{~B})}
$$

Dengan keterangan besar nilai parameter $\omega=1.03403-0.97223(B)$, parameter $\delta=1-0.94937(B)$, dan parameter $\emptyset=1-0.85705(B)$

\section{DAFTAR PUSTAKA}

Anggraeni, W., Boga, K., \& Mahananto, F. (2018). Performance of ARIMAX Model and Vector Autoregressive ( VAR ) Model in Forecasting Strategic Commodity Price in Indonesia. Procedia Computer Science, 124, 189-196. https://doi.org/10.1016/j.procs.2017.12.146

Anggraeni, W., Vinarti, R. A., \& Kurniawati, Y. D. (2015). Performance Comparisons between Arima and Arimax Method in Moslem Kids Clothes Demand Forecasting: Case Study. Procedia Computer Science, 72, 630-637. https://doi.org/10.1016/j.procs.2015.12.172

BPS. (2017a). Kabupaten Kendal Dalam Angka. Kendal: BPS Kabupaten Kendal.

BPS. (2017b). Pertumbuhan Ekonomi Indonesia Triwulan III-2017. In Th.XX (Vol. 11). https://doi.org/http://www.bps.go.id/brs_file/pdb_06feb12.pdf

BPS. (2018). Kabupaten Indramayu Dalam Angka (BPS Kabupaten Indramayu, Ed.). Indramayu: 2018.

Ekaputri, N. (2008). Pengaruh Luas Panen Terhadap Tanaman Pangan dan Perkebunan di Kalimantan Timur. 5(2), 36-43.

Febriansyah, F. U., \& Abadyo. (2013). Analisis Deret Berkala Multivariat Dengan Menggunakan Model Fungsi Transfer: Studi Kasus Curah Hujan di Kota Malang. 1-9.

Grandell, J. (2000). Time Series Analysis.

Haris, M. S. (2010). Implementasi Metode Fuzzy Time Series dengan Penentuan Interval Berbasis Rata-rata untuk Peramalan Data Penjualan Bulanan (Universitas Brawijaya). https://doi.org/10.13140/RG.2.2.36498.76481

Jumiati. (2016). Analisis Faktor-faktor yang Mempengaruhi Produksi Padi di Kecamatan Sinjai Selatan Kabupaten Sinjai. Universitas Negeri Makassar.

Kementrian Pertanian Indonesia. (2017). Statistik Pertanian 2017(M. S. Dr. Ir. AnaAstrid Susanti, M . S. Dr. Ir. Budi Waryanto, M. Dra. P. Hanny Muliany, Ss. SitiNur Sholikhah, M. S. Ir. Roch Widaningsih, M. Ir. Takariyana Heni A, \& D. R. Suryani, Eds.). Jakarta: Pusat Data dan Sistem Informasi Pertanian Kementrian Pertanian Republik Indonesia. 
Krismiasari, S. (2012). Peramalan Produksi Padi Di Kabupaten Kampar Dengan Metode Box-Jenkins. Retrieved from http://repository.uin-suska.ac.id/7572/

Makridakis, S., Wheelwright, S. C., \& McGEE, V. E. (1999). Forecasting: methode and application. Canada.

Mantiri, R. I. K. ., Rotinsulu, D. C., \& Murni, S. (2015). Analisis faktor-faktor yang mempengaruhi produksi padi sawah inbrida dan hibrida di Provinsi Lampung. Jurnal Sosial Ekonomi Pertanian Dan Agribisnis (SEPA).

Nisak, S. C. (2010). Analisis Peramalan Total Daya Listrik (VA) Berdasarkan Data Jumlah Pelanggan Menggunakan Fungsi Transfer Single Input. Malang.

Nugroho, K. (2016). Model Analisis Prediksi Menggunakan Metode Fuzzy Time Series. Infokam, 12(1), 46-50.

Pratiwi, S. H. (2016). Growth and Yield of Rice (Oryza sativa L.) on various planting pattern and addition of organic fertilizers. Gontor AGROTECH Science Journal, 2(2), 1-19. https://doi.org/10.21111/agrotech.v2i2.410

Purnomo, S. F. (2015). Penggunaan Metode ARIMA Untuk Prakiraan Beban Konsumsi Listrik Jangka Pendek. Universitas Negeri Semarang.

Rijanto, Soetriono, \& Suwandri, A. (2002). pengantar ilmu pertanian. Jember.

Sari, V. D., \& Sukojo, B. M. (2015). Analisa Estimasi Produksi Padi Berdasarkan Fase Tumbuh Dan Model Peramalan Autoregressive Integrated Moving Average (Arima) Menggunakan Citra Satelit Landsat 8 (Studi Kasus: Kabupaten Bojonegoro). Geoid, 10(2), 194-203.

Siswanti, K. Y. (2011). Model Fungsi Transfer Multivariat dan Aplikasinya Untuk Meramalkan Curah Hujan di Kota Yogyakarta (Universitas Negeri Yogyakarta). https://doi.org/10.1080/01402390.2011.569130

Sitohang, F. R. H., Siregar, L. A. M., \& Putri, L. A. P. (2013). Evaluasi Pertumbuhan dan Produksi Beberapa Varietas Padi Gogo (Oryza sativa L.) pada Beberapa Jarak Tanam Yang Berbeda. Jurnal Online Agroekoteknologi, 2(2337), 54-63. https://doi.org/10.14710/ik.ijms.20.2.87-100

Soekartawi. (2009). e-agribisnis: Teori dan Aplikasinya. Seminar Nasional Aplikasi Teknologi Informasi, 2007(Snati 2007), 19-25.

Tunjung. (2010). Analisis Efisiensi Pengelolaan Persediaan Bahan Baku Kedelai Pada Perusahaan Kecap PT. Lombok Gandaria Food Industry Palur Karanganyar (Universitas Sebelas Maret Surakarta). Retrievedfromhttps://eprints.uns.ac.id/4955/1/170722911201009451.pdf

Wei, W. W. S. (2006). Time series analysis univariate and multivariate methods. In D. Lynch (Ed.), Time series analysis univariate and multivariate methods (second edi). Retrieved from http://linkinghub.elsevier.com/retrieve/pii/016920709190015N 